http://jmscr.igmpublication.org/home/ ISSN (e)-2347-176x ISSN (p) 2455-0450 crossref DOI: https://dx.doi.org/10.18535/jmscr/v7i8.140

Original Article

\title{
An investigation of correlation of hypothyroidism with abnormalities in levels of lipid profile constituents-A case-control study
}

\author{
Authors \\ Dr Pooja Upadhyay ${ }^{1}$, Dr Krishna Narayan Tiwari ${ }^{*}$ \\ ${ }^{1}$ Resident, Department of Biochemistry, Hind Institute of Medical Sciences, Safedabad Barabanki \\ *Corresponding Author \\ Dr Krishna Narayan Tiwari
}

\begin{abstract}
Objective: To investigate correlation of hypothyroidism with abnormalities in levels of lipid profile constituents in a tertiary care hospital.

Methods: This was a case control study. The study group (cases) comprised of 50 subjects with hypothyroidism (22 subclinical hypothyroid and 28 overt hypothyroid). A total of 25 healthy subjects (controls) were also included in the study. Adults patients aged 18-60 years either of sex and high TSH contents (>5 $\mu \mathrm{IU} / \mathrm{mL}$ ) were included in the study. Fasting (12 to 14 hours) blood specimen (5 ml) from ante-cubital vein by venipuncture method in a vaccutainer without anti-coagulant was collected and transferred to the laboratory under aseptic and cold conditions.

Results: Analysis of variance showed that $T_{3}, T_{4}$ and TSH were significantly $(p<0.005)$ different among the groups. The post-hoc tests revealed that $T_{3}$ was found to be significantly $(p<0.01)$ higher among controls (106.94 \pm 29.36$)$ than overt hypothyroid $(65.55 \pm 37.83)$ patients. The post-hoc tests revealed that cholesterol, $L D L$ and triglycerides were significantly $(p<0.01)$ different to each other groups. $T_{3}$ and $T_{4}$ were significantly $(p<0.01)$ negatively correlated with all the lipid profile evaluated. However, TSH was significantly $(p=0.0005)$ positively correlated with all the lipid profile evaluated.

Conclusion: Hypothyroid patients with decreased levels of T3 \& T4 and increased levels of TSH are more susceptible to hypercholesterolemia, hyper triglyceridemia, compared to overt hypothyroid.

Keywords: Hypothyroidism, Lipid profile, Correlation.
\end{abstract}

\section{Introduction}

Hypothyroidism is a commonly prevalent endocrine disorder wherein gland becomes underactive and releases insufficient amount of thyroid hormone. Clinical presentation is well established; the classical changes include the slowing of physical and mental activities and that of all the body systems. Thyroid plays a vital role in digestion, heart \& muscle function, brain development, and maintenance of bones. The spectrum of clinical symptoms include fatigue, loss of energy, lethargy, weight gain, decreased appetite, cold intolerance, dry skin, hair loss, sleepiness, muscle pain, joint pain, weakness in the extremities, depression, emotional lability, mental impairment, forgetfulness, impaired memory, inability to concentrate, constipation, menstrual disturbances, impaired fertility, 
decreased perspiration, paresthesia and nerve entrapment syndromes, blurred vision, decreased hearing, fullness in the throat, hoarseness, neck pain, sore throat, or low-grade fever (Hashimoto thyroiditis) (Bello and Bakari, 2012).

Hypothyroidism is mainly of two types (i) overt hypothyroidism (OHT), and (ii) subclinical hypothyroidism (SHT). OHT is characterized biochemically by an increase in serum TSH levels and a decrease in serum $\mathrm{T}_{3}$ and $\mathrm{T}_{4}$ concentrations to levels below normal; whereas SHT is characterized by mild elevation in TSH and $\mathrm{T}_{3}$ andT $_{4}$ levels within normal range (American Association of Clinical Endocrinologists, 2002).

Thyroid gland secretes hormone $\mathrm{T}_{3}$ and $\mathrm{T}_{4}$ i.e. triiodothyronine and thyroxin respectively. These are iodine containing substances of physiological significance. Thyroid hormone regulates basic metabolic rate of target organs and is essential for normal growth of the human body (Guerrero et al, 1999). Cells of thyroid gland enrich actively the iodide ions from plasma. A normal thyroid gland produces all of circulating $\mathrm{T}_{4}$ and about $20 \%$ of circulating $\mathrm{T}_{3}$ (Surks et al, 2004). The $\mathrm{T}_{4}$, a prohormone, is converted to $\mathrm{T}_{3}$ (the active form of thyroid hormone). Nearly $80 \%$ of serum $\mathrm{T}_{3}$ is derived from de-iodination of $\mathrm{T}_{4}$ in peripheral tissues (Surks et al, 1973).

The objective of this study was to investigate correlation of hypothyroidism with abnormalities in levels of lipid profile constituents in a tertiary care hospital.

\section{Material and Methods}

This was a case control study conducted in the Department of Biochemistry, Hind Institute of Medical Sciences (HIMS), Safedabad, Barabanki, Uttar Pradesh. Patients attending Medicine OPD at HIMS were included in the study. The study group (cases) comprised of 50 subjects with hypothyroidism (22 subclinical hypothyroid and 28 overt hypothyroid). A total of 25 healthy subjects (controls) were also included in the study. Adults patients aged 1860 yearseither of sex and high TSH contents
(>5 $\mu \mathrm{IU} / \mathrm{mL}$ ) were included in the study. Subjects with active infection, history of smoking in recent past, on treatment of diabetes, hypertension, malignancy, pituitary \& rheumatologic diseases, on drugs affecting TSH, $\mathrm{T}_{3}$ and $\mathrm{T}_{4}$ levels (for example $\beta$ blockers, dopamine, proton, pump inhibitors) and after radiation treatment or thyroidectomy were excluded from the study. The study was approved by the Ethical Committee of the Institute and consent was taken from each participant before including in the study.

\section{Methods}

Fasting (12 to 14 hours) blood specimen $(5 \mathrm{ml})$ from ante-cubital vein by venipuncture method in a vaccutainer without anti-coagulant was collected and transferred to the laboratory under aseptic and cold conditions. Serum was separated after clotting the blood and centrifugation at 3,000 rpm for $5 \mathrm{~min}$ at room temperature. Serum samples were analyzed immediately or if needed stored at $20^{\circ} \mathrm{C}$ until analysis.

\section{Lipid Profile estimation}

A. Estimation of Serum Total Cholesterol: Enzymatically by coupled reaction method

B. Estimation of Serum Triglyceride: Enzymatically by coupled reactions.

C. Estimation of Serum HDL cholesterol: by blocking apo B containing lipoproteins and measuring cholesterol enzymatically

D. Estimation of Serum LDL Cholesterol using formula

$$
\begin{aligned}
{[\mathrm{TC}]=[\text { VLDL-C }]+[\text { LDL-C }]+[\text { HDL-C }] } \\
=[\mathrm{TC}]-[\mathrm{HDL}-\mathrm{C}+\mathrm{TG} / 5],
\end{aligned}
$$

values in $\mathrm{mg} / \mathrm{dL}$.

\section{Thyroid Function Tests}

- Thyroid Function Test (TSH): Using chemiluminescent (Autodelfia method)

- Triiodothyronine (T3): Using chemiluminescent method

- Thyroxine (T4): Using chemiluminescent method 


\section{Statistical Analysis}

The results are presented in frequencies, percentages and mean $\pm \mathrm{SD}$. The Chi-square test was used to compare categorical/dichotomous variables. The one way analysis of variance (ANOVA) followed by Bonferroni post-hoc tests was used to compare continuous variables among the groups. The Pearson correlation coefficient was calculated. The p-value $<0.05$ was considered significant. All the analysis was carried out on SPSS 16.0 version (Chicago, Inc., USA).

\section{Results}

The mean age of controls, subclinical hypothyroid and overt hypothyroid group was $33.08 \pm 12.61$, $38.95 \pm 13.08$ and $39.56 \pm 13.01$ years respectively. Majority of cases and controls were males. There was no significant ( $p>0.05)$ difference in age and sex among the groups showing comparability of the groups in terms of age and sex (Table-1).
Analysis of variance showed that $\mathrm{T}_{3}, \mathrm{~T}_{4}$ and TSH were significantly $(\mathrm{p}<0.005)$ different among the groups. The post-hoc tests revealed that $T_{3}$ was found to be significantly $(\mathrm{p}<0.01)$ higher among controls $(106.94 \pm 29.36)$ than overt hypothyroid $(65.55 \pm 37.83)$ patients. $T_{3}$ was also significantly $(\mathrm{p}<0.01)$ among patients of subclinical hypothyroid $(96.19 \pm 32.78)$ than overt hypothyroid $(65.55 \pm 37.83)$. Almost similar pattern was observed for $\mathrm{T}_{4}$ and reverse was for TSH (Table-2).

The analysis of variance showed that there was significant $(\mathrm{p}=0.0005)$ difference in cholesterol, LDL and triglycerides among the groups. The post-hoc tests revealed that cholesterol, LDL and triglycerides were significantly $(\mathrm{p}<0.01)$ different to each other groups (Table-3).

$\mathrm{T}_{3}$ and $\mathrm{T}_{4}$ were significantly $(\mathrm{p}<0.01)$ negatively correlated with all the lipid profile evaluated. However, TSH was significantly $(\mathrm{p}=0.0005)$ positively correlated with all the lipid profile evaluated (Table-4).

Table-1: Age and sex distribution among the groups

\begin{tabular}{|c|c|c|c|c|}
\hline Age and sex & $\begin{array}{c}\text { Controls } \\
(n=25)\end{array}$ & $\begin{array}{c}\text { Subclinical } \\
\text { Hypothyroid } \\
(n=22)\end{array}$ & $\begin{array}{c}\text { Overt } \\
\text { Hypothyroid } \\
(n=28)\end{array}$ & p-value ${ }^{1}$ \\
\hline Age in years, mean $\pm S D$ & $33.08 \pm 12.61$ & $38.95 \pm 13.08$ & $39.56 \pm 13.01$ & 0.15 \\
\hline \multicolumn{5}{|l|}{ Sex, no. (\%) } \\
\hline Male & $23(92.0)$ & $18(81.8)$ & $22(78.6)$ & \multirow{2}{*}{0.39} \\
\hline Female & $2(8.0)$ & $4(18.2)$ & $6(21.4)$ & \\
\hline
\end{tabular}

${ }^{1}$ ANOVA/Chi-square test

Table-2: Comparison of $\mathrm{T}_{3}, \mathrm{~T}_{4}$ and $\mathrm{TSH}$ among the groups

\begin{tabular}{|l|c|c|c|c|}
\hline Parameters & $\begin{array}{c}\text { Controls } \\
(\mathbf{n = 2 5})\end{array}$ & $\begin{array}{c}\text { Subclinical } \\
\text { Hypothyroid } \\
(\mathbf{n = 2 2})\end{array}$ & $\begin{array}{c}\text { Overt } \\
\text { Hypothyroid } \\
(\mathbf{n = 2 8})\end{array}$ & p-value $^{\mathbf{1}}$ \\
\hline $\mathrm{T}_{3}(\mathrm{ng} / \mathrm{dl})$ & $\left.106.94 \pm 29.36^{\mathrm{a}}\right)$ & $96.19 \pm 32.78^{\mathrm{b}}$ & $65.55 \pm 37.83^{\mathrm{a}, \mathrm{b}}$ & $<0.0005^{*}$ \\
\hline $\mathrm{T}_{4}(\mu \mathrm{g} / \mathrm{dl})$ & $8.36 \pm 2.13^{\mathrm{a}}$ & $6.52 \pm 2.54^{\mathrm{b}}$ & $3.12 \pm 3.03^{\mathrm{a}, \mathrm{b}}$ & $<0.0005^{*}$ \\
\hline $\mathrm{TSH}(\mu \mathrm{IU} / \mathrm{ml})$ & $1.91 \pm 1.18^{\mathrm{a}}$ & $11.20 \pm 4.6^{\mathrm{b}}$ & $66.10 \pm 34.47^{\mathrm{a}, \mathrm{b}}$ & $<0.0005^{*}$ \\
\hline
\end{tabular}

Table-3: Comparison of lipid profile among the groups

\begin{tabular}{|l|c|c|c|c|}
\hline Parameters & $\begin{array}{c}\text { Controls } \\
(\mathbf{n = 2 5})\end{array}$ & $\begin{array}{c}\text { Subclinical } \\
\text { Hypothyroid } \\
(\mathbf{n = 2 2})\end{array}$ & $\begin{array}{c}\text { Overt } \\
\text { Hypothyroid } \\
(\mathbf{n = 2 8})\end{array}$ & p-value $^{\mathrm{I}}$ \\
\hline Total cholesterol $(\mathrm{mg} / \mathrm{dl})$ & $163.4 \pm 18.84^{\mathrm{a}}$ & $197 \pm 48.66^{\mathrm{a}}$ & $262.22 \pm 43.92^{\mathrm{a}}$ & $0.0005^{*}$ \\
\hline HDL-cholesterol $(\mathrm{mg} / \mathrm{dl})$ & $54.36 \pm 8.52$ & $52.09 \pm 8.75$ & $49.48 \pm 6.830$ & 0.09 \\
\hline LDL-cholesterol $(\mathrm{mg} / \mathrm{dl})$ & $97.58 \pm 23.08^{\mathrm{b}}$ & $121.80 \pm 49.12^{\mathrm{b}}$ & $176.68 \pm 37.89^{\mathrm{b}}$ & $0.0005^{*}$ \\
\hline Triglycerides $(\mathrm{mg} / \mathrm{dl})$ & $92.80 \pm 36.99^{\mathrm{c}}$ & $135.64 \pm 48.92^{\mathrm{c}}$ & $185.93 \pm 58.60^{\mathrm{c}}$ & $0.0005^{*}$ \\
\hline
\end{tabular}


Table-4: Correlation of $\mathrm{T}_{3}, \mathrm{~T}_{4}$ and $\mathrm{TSH}$ with lipid profile parameters in overt \& subclinical in hypothyroid

\begin{tabular}{|l|c|c|c|}
\hline Parameters & Lipid profile & r value & P value \\
\hline \multirow{3}{*}{$\mathrm{T}_{3}$ ng/dl } & Total cholesterol & -0.42 & $0.0005^{*}$ \\
\cline { 2 - 4 } & LDL cholesterol & -0.33 & $0.003^{*}$ \\
\cline { 2 - 4 } & Triglycerides & -0.37 & $0.001^{*}$ \\
\hline \multirow{3}{*}{$\mathrm{T}_{4} \mu \mathrm{g} / \mathrm{dl}$} & Total cholesterol & -0.62 & $0.0005^{*}$ \\
\cline { 2 - 4 } & LDL cholesterol & -0.55 & $0.0005^{*}$ \\
\cline { 2 - 4 } & Triglycerides & -0.48 & $0.0005^{*}$ \\
\hline \multirow{3}{*}{$\mathrm{TSH} \mu \mathrm{IU} / \mathrm{ml} \mathrm{yl}$} & Total cholesterol & 0.73 & $0.0005^{*}$ \\
\cline { 2 - 4 } & LDL cholesterol & 0.69 & $0.0005^{*}$ \\
\cline { 2 - 4 } & Triglycerides & 0.65 & $0.0005^{*}$ \\
\hline
\end{tabular}

\section{Discussion}

A statistically significant decrease in $T_{3}$ and the T4 was observed in subclinical hypothyroid and in overt hypothyroid compared to control group. A statistically significant increase in TSH was seen in subclinical hypothyroid and in overt hypothyroid compared to controls. These findings were in accordance with study of Tayal et al (2009). Further, a pair wise comparison of $\mathrm{T}_{3}, \mathrm{~T}_{4}$ and $\mathrm{TSH}$ showed that the mean difference in $\mathrm{T}_{3}$ and $\mathrm{T}_{4}$ between controls and subclinical hypothyroid was statistically significant. These findings were in accordance with the study of Nananda et al (2004).

The mean difference of $\mathrm{T}_{3}$ and $\mathrm{T}_{4}$ between controls and overt hypothyroid was also statistically significant $(\mathrm{p}<0.05)$. These findings are in accordance with study of Tayal et al (2009) who claimed that $\mathrm{T}_{3}$ and $\mathrm{T}_{4}$ were significantly lower in subclinical and overt hypothyroid than controls. Thyroid dysfunction has a great impact on serum concentrations of lipids (Rizos et al, 2011; Maugeri et al, 1999). Substitution therapy is beneficial for patients with overt hypothyroidism improving lipid profile. However, whether subclinical hypothyroidism should be treated or not is a matter of debate. A general correlation between thyroid hormones and lipid metabolism is well established. Studies confirm the presence of an inverse relationship between thyroxin serum levels and cholesterol. Other studies demonstrate the influence of iodothyronine on the catabolism of VLDL, showing increase in LDL and VLDL fractions inuntreated hypothyroidism. The data concerning a definite correlation between thyroid hormones and triglyceride is morecontroversial. Elevation of triglycerides in hypothyroidism characterized by decreased clearance of VLDL-triglycerides due to reduced activity of lipoprotein lipase and of hepatic triglyceridelipase is reported by Prieur et al (2005).

In the present study, there was statistically significant increase in total cholesterol of subclinical hypothyroid and overt hypothyroid as compared to controls. Statistically significant increase was observed also in LDL cholesterol of subclinical hypothyroid and overt hypothyroid compared to controls. Statistically significant increase was also found in triglycerides ofsubclinical hypothyroid and overt hypothyroid compared to controls $(\mathrm{p}<0.01)$. These findings are in accordance with other studies (Efstathiadou et al, 2001; Costantini et al, 1998; Hueston and Pearson, 2004; Sheikh et al, 2009; Adrees et al, 2009).

Our study showed an insignificant increase in the mean difference of total cholesterol and LDL cholesterol between controls and subclinical hypothyroid. This finding is similar to the observation of Hueston and Pearson (2004).

HDL cholesterol was found to remain unchanged in subclinical hypothyroid andin overt hypothyroid compared to controls. This observation is similar to reports form Costantini et al (1998). However, Abrams and Grundy (1981) have reported hyper- 
triglyceridemia along with decreased HDL cholesterol level.

Pair wise comparison of parameters of lipid profile showed that the mean differences in total cholesterol, LDL cholesterol and triglycerides between subclinical and overt hypothyroid were statistically significant ( $<<0.01)$. Prakash and Lal (2006) have reported similar observation. Their study demonstrates that effect of hypothyrodism on lipid metabolism is more marked in patients with higher serum TSH levels. The mean difference of LDL cholesterol in subclinical hypothyroid compared to controls was insignificant. It has been observed by Hueston and Pearson (2004) also showing insignificant increase in LDL cholesterol among subclinical hypothyroid. The cause may be a less variation in thyroid hormones.

There was a statistically significant positive correlation between TSH and total cholesterol, LDL cholesterol and triglycerides among hypothyroid patients. This observation is in accordance with study done by Prakash and Lal (2006) which demonstrates that the effect of hypothyroidism in the lipid metabolism is more marked in patients with higher serum TSH levels. A statistically significant negative correlation was seen between $\mathrm{T}_{3}$ and total cholesterol and LDL cholesterol as deficiency of tri-iodothyronine down regulates LDL receptors.

One of the limitations of this study was small sample size. The studies with larger sample size and with long study duration are recommended to have robust findings.

\section{Conclusion}

Hypothyroid patients with decreased levels of T3 \& T4 and increased levels of TSH are more susceptible to hypercholesterolemia, hyper triglyceridemia, compared to overt hypothyroid. Dyslipidemia complications of hypothyroidism like hypercholesterolemia, atherosclerosis, can be prevented by monitoring thyroid hormone levels along with periodic assessment of lipid profile in hypothyroid patients.

\section{References}

1. Bello F. and Bakari A. G. Hypothyroidism in adults: A review and recent advances in management. Journal of Diabetes and Endocrinology 2012; 3(5): 57-69.

2. American Association of Clinical Endocrinologists. American Association of Clinical Endocrinologists Medical Guidelines for Clinical Practice for the Evaluation and Treatment of Hyperthyroidism and Hypothyroidism. Endocr. Pract. 2002; 8(6):457-469.

3. Guerrero A, Pamplona R, Postero-Otin M, et al. Effect of thyroid status on lipid composition and peroxidation in the mouse liver. Free Rad Biol Med 1999; 26(1-2): 73-80.

4. Surks MI, Ortiz E, Daniels GH, Sawin CT, Col NF, Cobin RH, Franklyn JA, Hershman JM, Burman KD, Denke MA, Gorman C, Cooper RS, Weissman NJ. Subclinical thyroid disease: Scientific review and guidelines for diagnosis and management. J. Am. Med. Assoc. 2004; 291(2):228-238.

5. Surks MI, Schadlow AR, Stock JM, Oppenheimer JH. Determination of iodothyronine absorption and conversion of Lthyroxine ( $\mathrm{T}$ 4) to L-triiodothyronine (T 3) using turnover rate techniques. J. Clin. Invest. 1973; 52:805-811.

6. Tayal D, Chawla R, Arora $\mathrm{S}$ et al. Dynamic Changes in Biochemical Markers of Renal Function with Thyroid Status - A Study in Indian Population. Internet Journal of Medical Update 2009;4(2):3641.

7. Nananda F. C, Surks M, Daniels G H. Subclinical Thyroid Disease Clinical Applications Scientific Review and 
clinical applications. JAMA.2004; 291: 239-243.

8. Rizos C V, Elisaf M S and Liberopoulos E N. Effects of Thyroid Dysfunction on Lipid Profile.The Open Cardiovascular Medicine Journal 2011;5:76-84.

9. Maugeri D, Santangelo A, Barbagallo P, Bonanno M R, Malaguarnera M, RizzaI, Speciale S, Tomarchio M, Curasì M.P, Panebianco P. Thyroid hormones and lipid metabolism in a group of patients over seventy. European Review for Medical and Pharmacological Sciences 1999;3:211216.

10. Prieur X, HubyT, Coste H et al. Thyroid Hormone Regulates the Hypotriglyceridemic Gene APOA5. The Journal of Biological Chemistry. 2005; 280(30):27533-27543.

11. Efstathiadou Z, Bitsis S, Milionis HJ, Kukuvitis A, Bairaktari ET, Elisaf MS, Tsatsoulis A. Lipid profile in subclinical hypothyroidism: is L-thyroxine substitution beneficial?.Eur $\mathrm{J}$ Endocrinol. 2001;145(6):705-10.

12. Costantini F, Pierdomenico S D, Cesare D Det al. Effect of Thyroid Function on LDL Oxidation. Arterioscler Thromb Vasc Biol 1998; 18:732-737

13. Hueston W J, Pearson W S. Subclinical Hypothyroidism and the Risk of Hypercholesterolemia. Ann Fam Med 2004;2:351-355.

14. Sheikh B A, Soomro A A, Soomro M A, Pirzado Z A et al. Lipid profile in primary hypothyroidism at Chandka Medical college Larkana. Medical channel 2009;15(4):15-18.

15. Adrees M, Gibney J, Saeity N and Boran G. Effects of 18 months of ${\mathrm{L}-\mathrm{T}_{4}}$ replacement in women with subclinical hypothyroidism. Clinical Endocrinology 2009;71:298-303.
16. Abrams JJ, Grundy SM. Cholesterol metabolism inhypothyroidism and hyperthyroidism in man. J Lipid Res 1981; 22: 323-338.

17. Prakash A and Lal AK. Serum lipids in hypothyroidism: Our experience. Indian Journal of Clinical Biochemistry, 2006; 1 (2) $153-155$. 